\title{
LAS MADRES SOLTERAS POR ELECCIÓN ¿Ciudadanas de primera y madres de segunda?
}

\section{SINGLE MOTHERS BY CHOICE}

\section{First Class Citizens and Second Class Mothers?}

\author{
Ana María Rivas \\ Universidad Complutense de Madrid. España \\ rivasant@cps.ucm.es \\ MARÍA ISABEL JOCILES \\ Universidad Complutense de Madrid. España \\ jociles@cps.ucm.es \\ Beatriz Moncó \\ Universidad Complutense de Madrid. España \\ bmonco@cps.ucm.es
}

\section{RESUMEN}

En este artículo se presentan algunos de los resultados de una investigación sobre los proyectos familiares de las mujeres que han optado por la maternidad en solitario, mediante la reproducción asistida, las relaciones sexuales y/o la adopción internacional. A través de sus discursos se analiza, en primer lugar, el conflicto entre su estatus de ciudadanas de pleno derecho, por el que han podido acceder, exitosamente, a la formación universitaria y al desempeño de empleos cualificados, y el estatus de madres aún condicionado por el modelo convencional de familia nuclear, conyugal y biparental, que sigue actuando como referente de legitimación para el resto de opciones familiares. En segundo lugar, se analizan las estrategias narrativas de legitimación que despliegan estas mujeres para obtener el reconocimiento social de su entorno familiar, laboral, de los amigos, institucional y, por último, la percepción carencial de su familia que ellas mismas acaban asimilando como efecto inesperado.

\section{Palabras Clave}

Adopción internacional, Ciudadanía, Donante conocido, Monoparentalidad, Procreación asistida.

\section{Abstract}

This article lays out the results of a study of family projects on women who have opted for single motherhood through assisted reproduction, sexual relations and/or international adoption. The course of these speeches is analyzed on a tri-fold approach. First, the speeches show the conflict between these women's status as full-fledged citizens, which has allowed them to successfully access university education and hold 
qualified positions, and their status as mothers that is still very much defined by the traditional model of the married, two-parent nuclear family, a model that continues to be the criteria for legitimizing all other family options. Secondly, the narrative strategies these women unfurl to gain social recognition in their respective family, work, friend and legal spheres are examined. Finally, these speeches permit to study the deficient perception of their family unit that many of these women end up assimilating as an unexpected side effect of their situation.

\section{KEYWORDS}

Assisted Reproduction, Citizenship, International Adoption, Known Donor, Single Motherhood.

\section{INTRODUCCIÓN: NUEVOS ESCENARIOS, NUEVOS MODELOS FAMILIARES}

Es ya un lugar común entre los sociólogos españoles (Flaquer y Soler 1990; Flaquer 1998; Iglesias de Ussel 1998; Alberdi 1999; Meil 1999; Jiménez 2005; Cea 2007, entre otros) señalar los cambios producidos en la estructura y morfología familiar ocurridos en España en los últimos treinta años de transición democrática, que han permitido su aproximación a los países considerados como más avanzados en los comportamientos y las relaciones familiares. Transformaciones que han supuesto la pérdida de hegemonía de la "familia tradicional" entendida como nuclear, biparental, heterosexual, autoritaria y asimétrica en la distribución sexual de los roles. Este hecho no implica, sin embargo, según estos mismos autores, su desaparición o sustitución, sino su coexistencia con otras opciones familiares, hasta ahora, socialmente estigmatizadas o reprobadas: las uniones consensuales; los matrimonios que voluntariamente deciden no tener hijos; las familias reconstituidas a partir de segundas o terceras nupcias; las parejas homosexuales; las relaciones LAT (living apart together), parejas estables pero con residencias separadas; las familias monoparentales, (no tanto las constituidas por viudos/as con hijos/as o separados/as con hijos/as, sino aquellas formadas por solteros/as que deciden iniciar un proyecto familiar a través de la adopción, la procreación asistida o las relaciones sexuales sin tener necesariamente una pareja).

Lo que hace de la pluralidad familiar un hecho relevante como indicador del cambio social no es tanto su carácter de novedad, puesto que siempre han coexistido modelos familiares diferentes al predominante, sino la admisión de su "normalidad" por el conjunto de la sociedad; la aparición de una actitud de tolerancia ante las formas diversas y diferentes de constituir una familia, y la emergencia de comportamientos considerados "ilegítimos" hasta hace unos años: la cohabitación, la separación, la homosexualidad y el nacimiento de hijos extramatrimoniales.

Los cambios que han incidido positivamente en estos procesos de normalización y visibilización son de varios tipos: demográficos (descenso de la nupcialidad y aumento de la cohabitación, disminución de la natalidad, aumento de las tasas de separación/ divorcio, incremento de la esperanza de vida, postergación de la formación de uniones y de la decisión de la maternidad); socioeconómicos (aumento de la educación, 
la formación profesional y la incorporación de la mujer al trabajo remunerado que han transformado su autopercepción y autovaloración como ya no destinada exclusivamente a desempeñar el rol de esposa, madre y ama de casa); culturales (nuevos valores de autorrealización, libertad en las decisiones de unión, autonomía, independencia, igualitarismo y deseo de un espacio personal, que han sustituido a los valores conservadores que destacaban el deber, el orden, el respeto por la autoridad tradicional, la responsabilidad y las obligaciones hacia los otros (Inglehart 1990; Beck y Beck-Gernsheim 2003; Jiménez Godoy 2005; Alberdi 1999); y tecnológicos (desarrollo y utilización de las técnicas de reproducción asistida).

Estos cambios se han ido plasmando en los discursos políticos identificados como más progresistas y en las correspondientes modificaciones legislativas sobre la familia, el matrimonio y la filiación, que han contribuido a crear un contexto institucional favorable a la libertad de los sujetos para construir sus proyectos familiares. Entre estas leyes destacaríamos las siguientes:

1) La legalización de los métodos anticonceptivos mediante la modificación del artículo 416 del Código Penal el 7 de octubre de 1978, por el que se legalizó la píldora como método anticonceptivo en España. Su despenalización supuso un importante paso en el proceso de normalización de la situación de la mujer y de las familias españolas, gracias a la separación entre sexualidad y procreación. Asimismo se despenalizó el adulterio, en el que la mujer estaba fuertemente discriminada.

2) Consecuencia del art. 39 de la Constitución Española de 1978 por el que se garantiza la igualdad de "los hijos ante la ley con independencia de su filiación, y de las madres, cualquiera que sea su estado civil", el 13 de mayo de 1981 se aprobó la ley de reforma del Código Civil en materia de filiación, patria potestad y régimen económico del matrimonio, que anulaba la distinción entre hijos "legítimos" e "ilegítimos", equiparándolos en sus derechos. Esta equiparación ha visto su última formulación con la ley de 8 de julio de 2005, por la que se modifica el reglamento del Registro Civil para eliminar la obligación antes impuesta, de anotar el nombre del padre (real o ficticio) en todo registro de nacimiento. Esto contribuirá a preservar la intimidad de aquellas madres solteras (y en menor medida de los padres), que no desean dejar constancia del nombre del otro progenitor, sin vínculos de filiación salvo los biológicos.

3) La ley de 22 de junio de 1981 por la que se aprobó el divorcio y la ley de 8 de julio de 2005 por la que se aprobó su reforma, con modificaciones sustanciales como: a) La posibilidad de solicitar tanto el divorcio como la separación judicial una vez hayan pasado tres meses desde la celebración del matrimonio, sin necesidad de solicitar previamente la separación para obtener el divorcio; en casos excepcionales, cuando se acredite riesgo para la vida, integridad física, libertad, integridad moral o libertad o indemnidad sexual del cónyuge demandante o de los hijos, no se exigirá plazo alguno para solicitar la separación o el 
divorcio. b) El hecho de no tener que justificar causa alguna de separación 0 divorcio. Tan sólo es suficiente el deseo de uno de los cónyuges de separarse o divorciarse. Con anterioridad a esta reforma, se exigía justificar una de las causas tasadas en el Código Civil. c) La creación del Fondo de Garantía de Pensiones. El Estado garantizará el pago de alimentos reconocidos e impagados a favor de los hijos e hijas menores de edad en convenio judicialmente aprobado 0 en resolución judicial, a través de una legislación específica que debería concretar el sistema de cobertura en dichos supuestos. El 7 de diciembre de 2007 se aprobó el Real Decreto sobre Organización y Funcionamiento del Fondo de Garantía del Pago de Alimentos.

4) Impulsada por los cambios sociológicos acaecidos en la estructura familiar, existe una normativa que define y contempla los requisitos y formalidades de las parejas de hecho. España, a diferencia de otros países europeos, no cuenta con una legislación en el plano nacional que equipare los derechos de las uniones de hecho y los matrimonios, sino que son las Comunidades Autónomas las que tienen competencia sobre los derechos y obligaciones de este tipo de uniones. Hasta el 2009, las Comunidades Autónomas que poseían una regulación autonómica propia eran: Cataluña, Aragón, Navarra, Comunidad Valenciana, Madrid, Islas Baleares, Andalucía, Asturias, Islas Canarias, Extremadura, País Vasco, Cantabria y Galicia.

5) La ley 13/2005, de 1 de julio, por la que se modificó el Código Civil en materia de derecho a contraer matrimonio entre personas de diferente o mismo sexo y a conceder a las parejas del mismo sexo el derecho a la adopción conjunta. Esta ley exigía, a su vez, cambios como los que se recogieron posteriormente en la orden Jus/568/2006 de 8 de febrero sobre modificación de modelos de asientos y certificaciones del Registro Civil y Libro de Familia, por la que se modifican el modelo oficial del Libro de Familia, la inscripción de matrimonio y de nacimiento, cambiando los términos marido y mujer, por cónyuge A y cónyuge $B$; padre y madre, por progenitor $A$ y progenitor $B$.

6) Las leyes sobre la reproducción asistida, entre las que están: la ley $35 / 1988$, de 22 de noviembre; la ley 45/2003 de 21 de noviembre; y la ley 14/2006, de 26 de mayo, sobre técnicas de reproducción humana asistida, en la que se reconoce el derecho de toda mujer mayor de 18 años, con plena capacidad de obrar, independientemente de su estado y orientación sexual a ser receptora o usuaria de las técnicas reguladas en la Ley. Asimismo, se recoge que en ningún caso, la inscripción en el Registro Civil reflejará datos de los que se pueda inferir el carácter de la generación, evitando así cualquier tipo de discriminación del menor nacido mediante estas técnicas.

La normativa, aprobada un año después de que se diera el visto bueno al matrimonio homosexual, exige que la donación de gametos (espermatozoides u óvulos) sea anónima. Con una excepción: cuando se utilice semen del marido de la mujer en cuyo útero se implanta el óvulo fecundado. La palabra "marido" 
seguía manteniendo una discriminación denunciada por algunos colectivos de lesbianas y fue sometida a la Comisión de Bioética del Ministerio de Sanidad la cual resolvió que si la Ley autoriza la donación entre parejas heterosexuales, también debe ser así entre las homosexuales. El órgano consultivo dependiente del Ministerio de Sanidad dejó claro en un dictamen emitido el pasado diciembre de 2008 que las parejas de mujeres homosexuales pueden usar las técnicas de fertilidad en igualdad de condiciones que las parejas de heterosexuales. Tras la resolución de la Comisión, el Gobierno tiene previsto realizar cambios en la ley que regula las técnicas de reproducción asistida. El objetivo, tal y como lo plantea el Ministerio de Justicia, es que no haya espacio a la interpretación. La intención es sustituir términos como marido por cónyuge; varón no casado, por persona no casada; o paternidad por filiación. La reforma afectará principalmente al artículo 5 de la ley de Reproducción Asistida.

7) Leyes sobre adopción: en España, la regulación de la adopción ha sido objeto de sucesivas reformas desde su redacción originaria en el Código Civil de 1889: ley 24 de abril de 1958; ley 7/1970, de 4 de julio; ley 11/1981, de 13 de mayo; ley 21/1987, de 11 de noviembre, reformada por ley orgánica 1/1996, de 15 de enero, de Protección Jurídica del Menor, de modificación parcial del Código Civil y de la Ley de Enjuiciamiento Civil, y por último la ley 54/2007, de 28 de diciembre, de adopción internacional. Todas estas leyes han ido introduciendo modificaciones derivadas de los nuevos requerimientos planteados por la aparición en España del fenómeno de las adopciones internacionales, entre ellas el derecho de los adoptados a conocer sus orígenes y el de los adoptantes 0 adoptante a solicitar que en la nueva inscripción conste su domicilio en España como lugar de nacimiento del adoptado, buscando la protección del menor y su no discriminación, al igual que veíamos antes con los menores procreados mediante técnicas de reproducción asistida.

De especial relevancia para el caso que aquí nos ocupa -las madres solteras por elección- son la ley 21/1987 de modificación de determinados artículos del Código Civil, la ley de enjuiciamiento civil en materia de adopción y la ley $35 / 1988$, sobre técnicas de reproducción asistida, por las que se permite a las mujeres acceder en solitario a la maternidad.

8) Hay que mencionar también la ley 39/1999, de 5 de noviembre, para promover la conciliación de la vida familiar y laboral de las personas trabajadoras, en la que se contempla la adopción o acogimiento entre las situaciones que dan derecho a la suspensión del contrato por maternidad.

Los contenidos de estas leyes responden a los fundamentos de la Constitución Española de 1978, como la promoción de la igualdad efectiva de los ciudadanos en el libre desarrollo de su personalidad (artículos 9.2 y 10.1), la preservación de la libertad en lo que a las formas de convivencia se refiere (artículo 1.1) y la instauración de un marco de igualdad en el disfrute de los derechos sin discriminación alguna por razón de sexo, 
opinión o cualquier otra condición personal o social (artículo 14). Valores consagrados constitucionalmente, y que, reflejados en la regulación de las normas, definen y delimitan el estatus del ciudadano y ciudadana en una sociedad libre, pluralista y abierta.

Todos estos cambios y modificaciones han potenciado la libertad de los sujetos en la configuración de sus proyectos familiares, particularmente, la libertad de las mujeres. Este es el caso de las madres solteras que han optado de manera deliberada y planificada por un proyecto familiar en solitario, a través de la adopción internacional, la procreación asistida y/o las relaciones sexuales. Proyectos familiares que se han visto apoyados y reforzados por esta "retórica de la igualdad" -en la política, los medios de comunicación, la vida pública y el sistema educativo- que cuestiona la polaridad de los géneros y propugna en su lugar la igualdad de derechos y oportunidades, haciendo posible la diversidad y pluralidad de estilos de vida, personales y familiares.

\section{OBJetivos e hIPÓTESIS}

En este artículo se presentan algunos de los resultados de una investigación aún no finalizada ${ }^{1}$, que tiene como uno de sus objetivos principales el estudio de los proyectos familiares de las mujeres que han optado por la maternidad en solitario -sin pareja-, a través de la reproducción asistida, las relaciones sexuales y/o la adopción internacional. El aumento del número de mujeres que responden a este perfil, solteras de forma originaria y elegida, resulta difícil de cuantificar dado que las estadísticas oficiales no permiten distinguir si las mujeres son solteras de forma originaria o sobrevenida, si lo son de forma planeada o no; criterios fundamentales para poder caracterizar al colectivo. Así y todo, según las cifras aportadas por González et al. (2008), podemos estimar que es un colectivo que ha ido en aumento en la medida en que también lo han ido haciendo las madres solteras en general, dado el incremento notable de los hijos nacidos de madres solteras en España, que ha pasado del 2,03\% en 1975 al 26\% en 2005. Si atendemos al grupo de madres solteras de 350 más años, mujeres con toda seguridad adultas y maduras, tal y como señalan estas mismas autoras, el incremento en los últimos 20 años es también espectacular: la maternidad de solteras ha subido en este grupo más del $300 \%$ : de un $6,3 \%$ en 1985 a un $20,5 \%$ del total de nacimientos en mujeres de ese grupo de edad en 2005 (2008:7-8).

La hipótesis de partida, congruente con los planteamientos de Bock (2000), Ben-Ari y Weinberg-Kurnik (2007) y May (2004), plantea la contradicción en la que se sienten atra-

\footnotetext{
1 "Madres solteras por elección: proyectos familiares y políticas públicas" (Fundación Santander-Complutense PR34/07), realizada en la Comunidad de Madrid (España), por un equipo de investigadores compuesto, además de por las autoras del artículo, por Fernando Villaamil, así como por Pablo Díaz, colaborador de investigación. Estudio que ha continuado con el proyecto I+D+i "Monoparentalidad por elección: estrategias de autodefinición, distinción y legitimación de nuevos modelos familiares", FEM-2009-07717.
} 
padas estas mujeres, entre su estatus de ciudadanas de pleno derecho por el que han podido acceder, exitosamente, a la formación universitaria y al desempeño de empleos cualificados, de acuerdo a los valores democráticos de igualdad, libertad y emancipación, y el estatus de madres aún condicionado por el modelo convencional de familia nuclear, conyugal y biparental, que sigue actuando como referente de legitimación para el resto de opciones familiares.

Lo que se presenta en este artículo es un análisis pormenorizado de dicho conflicto a partir de los datos de nuestra propia investigación. Para ello se analizan, por un lado, las estrategias de legitimación que despliegan estas mujeres para obtener el reconocimiento social de su entorno familiar, laboral, de los amigos, institucional; y por otro, los ejes narrativos sobre los que descansa la descripción de sus experiencias: en primer lugar, su autopercepción como mujeres empoderadas, autónomas e independientes (lo que les ha permitido reunir las condiciones materiales para embarcarse en un proyecto familiar en solitario); y en segundo lugar, la percepción y constatación de las resistencias sociales que existen a este tipo de proyectos familiares por desafiar el paradigma aún dominante de la familia convencional; que si bien puede estar siendo cuestionado, sigue actuando, como ya hemos indicado, de modelo legitimador.

\section{Metodología}

En el contexto de la investigación cualitativo-etnográfica con la que hemos dotado de base empírica a este artículo, hemos realizado 52 entrevistas cualitativas a madres solteras por elección (MSPE) madrileñas: 33 de ellas son mujeres que han adoptado y/o están en proceso de adopción (en 32 casos, internacional y en 1, nacional); 16 han acudido a las técnicas de reproducción asistida, 2 de las cuales han hecho (o están haciendo) también uso de la adopción para tener a su segundo hijo, y 3 han recurrido a la fecundación sexual con "donante conocido". También se han efectuado entrevistas, hasta completar un total de 60, a padres solteros por elección (4), hijos de las MSPE (1) -y está previsto hacérselas a profesionales (3) que intervienen con el colectivo en los ámbitos de las adopciones y las clínicas de reproducción asistida-. De estas 60 entrevistas, aquí sólo tomamos en consideración las efectuadas a las MSPE dado el tema que, como hemos dicho, vamos a abordar. Para la realización de estas entrevistas se partió de un guión que, usado de manera flexible y abierta, giró en torno a los siguientes ejes temáticos: datos sociodemográficos de la mujer, trayectoria laboral y socio-afectiva, toma de decisiones sobre el proyecto familiar, vía adoptada de acceso a la maternidad, motivaciones, inicio del proceso, incorporación del hijo/a a la familia, crianza, escolarización, reacción del entorno ante su proyecto familiar, recursos y demandas a las administraciones públicas, asociacionismo y pertenencia a redes de monoparentales y expectativas de futuro. Las entrevistas fueron grabadas y posteriormente transcritas literalmente para su análisis. 
Asimismo, en el periodo de duración de la investigación, esto es, en el 2008-09, hemos recogido datos mediante observación sistemática (con una media de 1 hora de observación al día) en diversos foros de internet creados por y para ellas²: en particular, en los denominados Madres Solteras por Elección y Adoptarsiendosoltero; hemos acudido a encuentros de carácter informal entre grupos restringidos de MSPE que son amigas/conocidas, así como a diversas "kedadas", esto es, a las reuniones presenciales de algunas de estas comunidades virtuales, realizando observación participante durante las mismas y, de un modo más continuado, en las organizadas por Adoptarsiendosoltero y Adoptanepa/ ${ }^{3}$, pues esta última (que se celebra en Madrid con una periodicidad de una vez al mes), aunque abierta a todo tipo de familias que han adoptado o están adoptando en Nepal, es frecuentada de manera casi exclusiva por monoparentales. Los datos obtenidos a través de la observación han sido registrados de forma sistemática y continua en un diario de campo, en el que se ha ido plasmando paralelamente un análisis provisional de los datos recabados y una reflexión sobre el propio proceso de observación. En todo momento se ha tratado de distinguir entre lo que son datos empíricos de observación e interpretaciones de los investigadores, a partir de los mismos. El número de observaciones así como de entrevistas realizadas se ha fijado a partir del principio de saturación. Como procedimiento de validación se ha usado asimismo la devolución de los primeros resultados al propio colectivo en forma de textos y de conferencias, reincorporando en los documentos finales el feed-back establecido con los sujetos investigados.

Finalmente, hemos recopilado información documental derivada de diversas fuentes: manuales de evaluación de la idoneidad y de formación de padres adoptivos, dirigidos a los profesionales de la Comunidad de Madrid que trabajan en el ámbito de las adopciones internacionales; resúmenes estadísticos; blogs y webs ${ }^{4}$ creadas por las MSPE residentes en este ámbito territorial.

Estos foros y espacios de encuentro han servido también, al igual que los contactos personales de algunos miembros del equipo de investigación, para acceder a la muestra de las MSPE a entrevistar, pues han sido los procedimientos a través de los cuales se han contactado; o, cuando no, han constituido el punto de arranque para la implementación del sistema de "bola de nieve". Estos procedimientos se han utilizado igualmente en otras investigaciones realizadas en España sobre las MSPE, como la de Jordana (Jordana 2007:10) y -en lo que atañe a su vertiente cualitativa- de González (Gonzá-

\footnotetext{
${ }^{2}$ De modo menos sistemático, una de nosotras ha observado en ellos desde hace unos cuatro años, en el marco de otra investigación sobre el papel de las instituciones intermediarias de adopción internacional en la conformación de los roles paternos -véase, por ejemplo, Jociles y Charro (2008)-.

${ }^{3}$ Adoptanepal: http://es.groups.yahoo.com/group/adoptanepal/ y http://elistas.egrupos.net/lista/adoptanepal; Adoptarsiendosoltero: http://es.groups.yahoo.com/group/adoptarsiendosoltero/ y http://elistas.egrupos.net/ lista/adopcionsiendosoltero/; MSPE: http://madremspe.multiply.com/.

${ }^{4}$ Tales como Masola (http://www.masola.org/), Yendo a por el segundo (http://mspe.blogspot.com/), Esperando a Raquel (http://mascercaderaquel.blogspot.com/), Asociación Madres Solteras por Elección (http://madressolterasporeleccion.org/index.php), etc.
} 
lez et al. 2008:30), si bien en esta segunda se ha recurrido asimismo a otros medios de captación de informantes, como pedir colaboración a los Servicios de Adopción de la correspondiente Comunidad Autónoma o a las clínicas de reproducción asistida. El equipo de María del Mar González entrevista a 23 MSPE, de las cuales 16 lo son por adopción, 4 por reproducción asistida y 3 por fecundación sexual, teniéndose en cuenta, por otra parte, que en el caso de estas últimas no se trata de mujeres que planificaran previamente su embarazo, sino que se embarazaron accidentalmente y aceptaron la situación una vez se había producido, por lo que estrictamente hablando no se ajustan a la definición de monoparentalidad electiva a la que se recurre en nuestra investigación. En cuanto al trabajo de Jordana, de las 12 MSPE que formaron parte de su muestra, 10 lo son por adopción y las 2 restantes por "fecundación sexual" planificada. Para mencionar únicamente un estudio más, el de Hertz se basa en 65 entrevistas en profundidad a madres solteras heterosexuales, distinguiendo cuatro vías de acceso a la maternidad en solitario por elección: fecundación asistida con donante desconocido, la fecundación sexual con donante conocido, la adopción y -como el equipo de González- el embarazo aceptado a partir de una concepción no planificada (Hertz 2006:3).

Las MSPE que hemos entrevistado han sido las que se han definido a sí mismas como tales, al responder a nuestra llamada de contactar con mujeres que fueran o estuvieran en camino de convertirse en "madres solteras por elección", esto es, las que se han auto-identificado y/o han sido identificadas de esta manera por otras. Así, si analizamos el perfil que presentan, por ejemplo, las 52 entrevistadas de nuestro estudio, encontramos que, a parte de ciertas características socio-económicas ya resaltadas por otros trabajos (mujeres que, en su gran mayoría, se convierten en madres a edades maduras -por lo general, entre los 35 y los 45 años-, tienen un alto nivel académico, son económicamente solventes, se inscriben en las clases medias-altas, etc.), todas comparten otro conjunto de rasgos que nos permiten conocer la definición que de sí mismas elaboran en cuanto MSPE y que, por lo indicado más arriba, nos han permitido también delimitar conceptualmente el universo de nuestra investigación; un universo que, con todo, está conformado no sólo por las MSPE que han sido entrevistadas, sino asimismo -como se ha dicho- por otras que frecuentan espacios que les están específicamente destinados (virtuales y presenciales).

Para el análisis de los datos obtenidos, hemos utilizado procedimientos cercanos a la Grounded Theory (Strauss \& Corbin 1998), especialmente los que tienen que ver con la fundamentación de los códigos y categorías desde los discursos y las prácticas de las participantes. A partir de una inmersión en el material hemos generado en primer lugar, códigos próximos al material empírico analizado que, posteriormente, ha sido subsumido en categorías analíticas de carácter más general y teórico. Posteriormente, estas categorías han sido objeto de una codificación axial y selectiva, estableciéndose las relaciones más relevantes entre ellas. 


\section{MUJERES LIBRES EN SOCIEDADES DEMOCRÁTICAS FRENTE A MADRES CONDICIONADAS EN SOCIEDADES PATRIARCALES}

Los discursos de estas mujeres describen a un colectivo perteneciente a una generación -la de los años 60/70 - que ha interiorizado y ejercido los nuevos valores de autorrealización, independencia y autonomía, no sólo sobre su propio cuerpo, sino también sobre la configuración de su vida y su futuro. Nos encontramos con relatos biográficos pautados por el cumplimiento progresivo de las expectativas sociales depositadas en las mujeres de esta generación: estudio y formación, incorporación al mercado laboral, independencia económica, emancipación familiar... Si hasta hace treinta años, el imperativo social de las mujeres -disfrazado de destino natural- era la maternidad vinculada al matrimonio, como acceso a la seguridad económica y al estatus social, ahora parece que la mujer no necesita casarse ni tener hijos para realizarse, sino que puede y debe encontrar otros ámbitos de autorrealización, como el económico, el profesional y el laboral. Tener un título universitario, conseguir un empleo estable y ganar su propio dinero se ha convertido en un elemento nuclear de los proyectos vitales de estas mujeres, que les proporciona autoconfirmación y autoconfianza, reconocimiento por parte de los demás y posibilidades de afirmar sus derechos y exigencias, entre los que está experimentar nuevas formas familiares, todavía minoritarias, como la maternidad en solitario.

Su autopercepción como mujeres libres en sociedades democráticas, capaces de ejercer el rol de ciudadanas de pleno derecho y de participar en la construcción de una sociedad plural y abierta, va paralela a su autodefinición como madres solteras por elección. Tanto las mujeres adoptantes como las que optan por la procreación asistida o donante conocido experimentan la maternidad en solitario como una vía de empoderamiento, de potenciación, que supone ganar poder por sí mismas y para sí mismas, tener capacidad de iniciativa y de acción deliberada. La opción por la maternidad en solitario representa para ellas otra experiencia de emancipación y auto-realización -junto con la profesional y laboral- que afirma su imagen de mujeres autónomas e independientes:

$1^{\circ}$.- Son mujeres que ejercen una maternidad responsable. Adoptan la decisión de ser madres cuando reúnen las condiciones materiales (empleo, vivienda, salario) y afectivas (estabilidad emocional) que creen necesarias para tener un hijo en solitario; calculan las consecuencias de su decisión y toman conciencia de que son ellas las que deben asumirlas con sus propios medios y recursos, sin depender de otros, ya sea la red familiar, los servicios sociales u otro tipo de ayudas públicas:

Yo no hago planes que no dependan de mí. Quiero decir, yo solamente planifico lo que soy yo capaz de sacar adelante, entonces no voy a hacer yo planes de adoptar un niño pensando en que luego mi madre me lo va a cuidar... (Alicia, 45-50 años, soltera, estudios universitarios, ingeniera, adopción en proceso en Nepal; entrevista febrero 2008) 
$2^{\circ}$.- Son mujeres independientes, autosuficientes, autónomas, seguras, resueltas. Comunican la decisión una vez adoptada, no consultan ni piden consejo; están acostumbradas a gestionar su vida independientemente de lo que puedan decir los demás, sin dar cuenta a nadie. La decisión la adoptan unilateralmente y sólo después la hacen pública a sus familiares y amistades, al igual que el resto de decisiones que han tenido que ir tomando a lo largo de su trayectoria vital. Esto mismo se pone de manifiesto en el estudio de González (et. al., 2008).

No. Yo no lo consulté... Lo quería madurar yo sola. O sea hubo un momento en que lo lancé a la que en ese momento era mi amiga más íntima. Y me di cuenta de que ella me quería influenciar. Entonces, decidí que era algo tan importante en mi vida, que lo tenía que decidir yo sola. O sea, no quería recibir influencias de nadie, ni positiva, ni... o sea, ni hacia un sentido ni hacia el otro. (Carmela, 35-40 años, divorciada, estudios secundarios, analista informático, hija de 0-5 años por reproducción asistida; entrevista febrero 2008)

$3^{\circ}$.- Son mujeres que, con sus actos electivos, se convierten en agentes creadores de nuevos modelos de maternidad, familia y parentesco. Si bien algunos autores (Alberdi 1999; Alberdi, Escario y Hainovich 1984) señalan como rasgos distintivos de la "nueva familia": 1) la pérdida de centralidad de la maternidad para las mujeres, que ha pasado de ser una función obligada portadora de la identidad femenina a ser una función opcional y, 2) la revalorización de la pareja, que se justifica a sí misma, sin necesidad de recurrir a los hijos para su legitimación, no parece ser éste el caso del colectivo de las MSPE, cuya opción familiar demuestra una relación inversa: lo central es la maternidad; el deseo de los hijos por sí mismo, sin necesidad de recurrir a la pareja para su legitimación. La ruptura conceptual que protagonizan estas mujeres es triple. En primer lugar, disocian la maternidad de la pareja; para ser madres no necesitan una pareja:

Yo había tenido otras parejas y... por ejemplo, la última que tuve resulta que era un chico que estaba separado ¿no? Y tenía dos niños y no quería tener más hijos, porque él como que ya había cumplido. Era una postura que a mí me parecía muy egoísta ¿sabes? Entonces dije "¿por qué tengo yo que estar condicionada a un hombre para poder tener un hijo?" Es que me parecía absurdo, y además en estos tiempos. (Lidia, 40 años -comenzó con + 35-, estudios universitarios, secretaria, adopción en proceso en China, comienzo 2004; entrevista marzo 2008)

En segundo lugar, separan la pareja de la paternidad, las figuras de pareja y padre, es decir, ni el padre biológico tiene por qué ser la pareja ni la pareja tiene por qué ser el padre biológico ni el padre social. De hecho, algunas han tenido pareja, la tienen actualmente o no renuncian a la posibilidad de tenerla, pero distinguiendo claramente que ello no implica asumir ni un estatus ni un rol de paternidad: 
No, si él (su actual pareja) está encantado. Si a él lo que le gustaría es tener un hijo. Pero bueno, pues... A ver, es que va a ser mi hijo, no va a ser de los dos. Pero... él se lo está tomando... Tiene mucha ilusión, si ya tengo yo cosas que ha traído para el niño. No, al contrario, yo creo que le va a venir bien, porque una figura masculina también viene bien. Quiero decir que a mí me parece estupendo que él también esté ilusionado con el tema. jAunque no va a ser su padre! Pero... a mi eso me parece bien [...] esto es un proyecto mío; que estoy yo en él y lo llevo yo adelante. (Alicia, 45-50 años, soltera, estudios universitarios, ingeniera, adopción en proceso en Nepal; entrevista febrero 2008)

En tercer lugar, del hecho de proyectar una maternidad sin pareja y de considerar una pareja sin estatus ni rol de paternidad, descubren a través de su experiencia que es posible conformar una estructura familiar sin la figura del padre, tanto en sentido biológico, social, como simbólico; lo que significa la posibilidad de crear una familia sin figura paterna pero, al mismo tiempo, sin renunciar a la pareja, diferenciando, así, la "familia" de la "pareja":

Entonces, claro, yo me planteé: ¿y si yo encuentro una pareja? ¿y si esa pareja no quiere? Es que, para mi es más importante ahora mismo la maternidad que el tener una pareja. Entonces, bueno, el día de mañana se verá, puedes tener una pareja. Además, ¿sabes una cosa?, que te das cuenta que... o lo que pensamos mucha gente que estamos en el foro es que una cosa es la familia y otra cosa es la pareja. Se empieza a ver... O muchas mujeres [...] nosotras consideramos que la familia es: tus padres, tus hijos... unos lazos de sangre; y la pareja, no. Porque actualmente... Mi experiencia, como la de todas, ¿eh? Es decir, yo he tenido una pareja, me ha ido mal... Es decir, las parejas van y vienen, no forman parte de tu familia. Entonces, establecemos una diferencia entre lo que es familia -que queremos tener nuestra familia, con un hijo, dos, padres... es decir, familia-, y lo que es la pareja. Entonces, establecemos esa separación. Entonces, yo no considero que mi pareja sea mi familia. Mi pareja "puede" formar parte de mi familia, pero no necesariamente. (Salomé, 39 años, divorciada, estudios universitarios, profesora instituto, reproducción asistida en proceso; entrevista mayo 2008)

El hecho de que no existan de referentes les obliga a inventar y ensayar respuestas a estas nuevas situaciones, derivadas, fundamentalmente, de la separación entre biparentalidad y crianza de los hijos, lo que plantea cuestiones diferentes según la vía de entrada a la maternidad: ausencia del padre en el caso de las que optan por la procreación asistida con donante anónimo; duplicidad de familias y pluriparentalidad en el caso de las que van por adopción internacional; parentesco electivo para las que se deciden por donante conocido.

Porque yo no me esperaba que tuviera una madre, no me lo esperaba. Yo me esperaba un niño, además, sin historia ¿no? Sin pasado y sin nada. Creía que era asi [...] Pero 
es lo que me pilló a mí más descolocada. Porque no me lo había planteado. (Chavela, 44 años -comenzó con unos 40-, soltera, estudios universitarios, trabaja en educación, 1 hijo de 5 años de Etiopía; entrevista marzo 2008)

Conscientes de estar contribuyendo a crear un nuevo tipo de familia monoparental, muy diferente a las situaciones de maternidad sobrevenida conocidas hasta ahora, se convierten en actores políticos, que reivindican y reclaman su derecho a existir como familia:

El perfil de las asociaciones, en algunos casos, es de carácter asistencial en cuanto a casas de acogida o pisos de apoyo o desde... de ayuda. Que eso no quiere decir que nosotras no nos echemos una mano porque... pero no es el objetivo ${ }^{5}$. Normalmente el objetivo es el ser un grupo... o sea, conocernos a nivel de familia y que nuestros hijos nos conozcan, reflexionar... Ahora tenemos por ejemplo, la semana que viene vamos a ver una charla de una psicóloga, pues para reflexionar sobre aspectos de la maternidad, pero de nuestro modelo de familia. Sobre cómo contárselo, cómo contar en diferentes situaciones las situaciones de reproducción asistida, las de donante conocido... (-¿Cómo contarlo a...?) A los niños. O sea, por un lado, en cuanto a lo lúdico; por otro lado el cómo plantear la decisión de crear nuestras familias con los niños y cómo... Y por otro lado, reivindicar un poco ante la sociedad o en las cosas en las que vayan surgiendo, que los modelos de familia van cambiando. Pues a nivel de educación, de... cómo se trata esto, vamos, pues en los libros de texto, en los coles... Pues que se vayan... No sé, profundizar en eso e ir ampliando el modelo a... incorporando el modelo a otros entornos. (Nora, 30-35 años -comenzó con 25/30-, soltera, estudios universitarios, trabajo en intervención socio-educativa, 1 hija de 0-5 años con "donante conocido" y embarazada de 8 meses del mismo donante; entrevista marzo 2009)

Asumiendo el potencial transformador de su decisión, llegan a proponer un nuevo término para identificar y definir su opción familiar: "familia marental" (http://madremspe. multiply.com/).

Junto a este hilo narrativo de empoderamiento y autoconciencia de las posibilidades y condiciones que actualmente existen para que las mujeres puedan explorar nuevos proyectos personales y familiares, nos encontramos en sus discursos, con otro hilo narrativo que reafirma las normas culturales dominantes que identifican a la familia convencional, conyugal y biparental, como la estructura familiar legítima. Lo que evidencia la contradicción entre dos niveles discursivos: uno que responde al estatus de mujeres

\footnotetext{
${ }^{5}$ Hace referencia a los objetivos de la Asociación Madres Solteras por Elección que aparecen en su página web http://www.madressolterasporeleccion.com. El primer objetivo es: "PROMOVER nuestra asociación para dar a conocer un nuevo tipo de familia en la sociedad, y sensibilizar a ésta para que la maternidad en solitario sea aceptada como una opción responsable de la mujer, que se ha realizado de forma libre y voluntaria independientemente de su estado civil".
} 
como ciudadanas libres e iguales en sociedades democráticas; y otro, que responde al estatus de mujeres como madres condicionadas por el paradigma patriarcal, aún vigente en esas mismas sociedades. Disonancia cognitiva y tensión narrativa que han señalado también otros autores como Ben-Ari y Weinberg-Kurnik (2007) en su estudio sobre madres solteras en Israel.

La persistencia del modelo normativo de familia conyugal y biparental aparece en sus relatos a través de las resistencias que encuentran en su entorno social (familia, compañeros, amigos, profesionales de la educación, expertos en la adopción y procreación asistida) y que ponen en duda la aceptabilidad y legitimidad de su familia monoparental. Las expectativas sociales depositadas sobre las mujeres, como sujetos libres para escoger y ejercer un estilo propio de vida, parecen incompatibles con las expectativas sobre ellas como madres, en un sistema cultural de parentesco, en el que se sigue equiparando maternidad con emparejamiento, y considerando la biparentalidad como el marco ideal para la crianza de los hijos.

La persistencia del supuesto patriarcal de que los hijos deben ser engendrados en una relación de pareja -y por lo tanto heterosexual-, sea ésta de hecho o de derecho -lo que no modifica el supuesto-, explica las reacciones a las que se enfrentan estas mujeres cuando hacen pública su opción por una maternidad en solitario. Las resistencias que constatan en sus entornos inmediatos reflejan la existencia de predisposiciones culturales a seguir creyendo que la pareja es el marco idóneo para la procreación y la crianza de los niños. Estas reacciones son de diferente tipo:

De sorpresa e incredulidad

La gente se queda clavada, que es para hacerles una foto: "jay! ¡No sabía que estabas casada!" "No, si no lo estoy. Soy madre soltera, por elección. Ha sido in vitro" ¿sabes? (Norma, 38 años -comenzó con 30-, divorciada, estudios secundarios, directora de entidad privada, en proceso de reproducción asistida; entrevista mayo 2009)

De oposición y rechazo

Entonces yo en esas que estaba pues tenía que ir al ginecólogo y dije [...] y yo esto planteándome un embarazo [...], pero no sé, no me veía yo muy preparada. Yo estoy operada, a mi me extirparon la glándula vaginal derecha y tuve una endiometrocis, entonces cuando estuve con el ginecólogo le dije ¿el seguro cubre el tema de la inseminación?, me dijo "sí, sí, claro, si tienes algún problema en la pareja", le digo no, es que sería yo sola y me dice "ah, no", (es el típico privado)... fue súper frío. (Gladis, 41 años, divorciada sin hijos previos -comenzó con 40- estudios universitarios, trabajo en el ámbito de la educación, en proceso de adopción en Vietnam; entrevista marzo 2008) 
De silencio y mutismo

Sí. Al principio nadie... todo el mundo se quedó... El año pasado por Navidad, esta Navidad no, la anterior, me acuerdo que lo dije en mi casa, pero, en realidad, lo que yo estaba pensando era la inseminación, ya que había ido a la clínica y todo. Digo: "Voy a lanzar el globo-sonda". Le dije a mi madre: "Mamá, voy a adoptar", "iUh!" Se echó las manos a la cabeza, "¿Uh, qué vas a hacer, te vas a meter en un lío! Ése niño bien, pero tú te vas a meter en un lío". Dije: "Madre mía! Si supiera qué es lo que voy a hacer". (Risa) Y lancé el globo-sonda, y todo el mundo hizo oídos sordos. Nunca nadie me volvió a preguntar, "¿Y qué tal?" Ni mis hermanas, nada. Todo el mundo como si no hubiera dicho nada. [...] (Jimena, 40 años -empieza con 39-, soltera, estudios secundarios, conserje y está haciendo estudios universitarios; adopción en proceso en Vietnam; entrevista mayo 2008)

De sospecha y duda

Me preguntaron pues por toda mi vida, desde que nací, vamos, y fue mas incisiva la trabajadora social que el psicólogo, es curioso es como si se hubieran invertido los papeles, el psicólogo me dio su visto bueno (risas) muy rápido y la trabajadora social haciéndome una serie de preguntas sobre, ¿por qué?, ¿cómo?, ¿parejas?, ¿ruptura de parejas? o ¿conflictos anteriores?, ¿ansiedades?, todo eso lo removió la trabajadora social con preguntas directas. [...] Yo creo que son estereotipos como tantísimos otros que hay sobre las personas, yo no sé, debe ser así, que lo lógico es tener pareja y que si no la tienes es por algo y a lo mejor es algo grave (Risas) (Estrella, 45-50 años, soltera, estudios universitarios, profesional en una entidad privada, 1 hija de 5-10 años adoptada en Etiopía; entrevista mayo 2008)

De inseguridad e incertidumbre

En el trabajo... me acuerdo que tenía yo un jefe -al que quiero mucho- entonces, que le quiero mucho ahora y le quería antes, que solamente me dijo... cuando le conté cómo lo iba a hacer, me dijo: "¿Pero van a poder comprobar si el donante es una buena persona?" Y le dije: "Pues no, creo que no lo van a poder comprobar". Y dije: "Pff... Me mosquea eso un poco". (risa) Y digo: "Bueno, ya intentaremos que aunque los genes vengan de una mala persona, pues que con la educación lo corrijamos" (risas). (Angelina, 45-50 años - comenzó con 35/40-, soltera, estudios universitarios, empleada en organismo público, 1 hija de 10 años por reproducción asistida; entrevista febrero 2008). 
De condescendencia e indulgencia, cuando se ha intentado formar una familia tradicional sin conseguirlo

O sea, mis padres han visto que yo he intentado formar una familia y se me ha desmoronado entre los dedos. jNo pasa nada! Se llora, se curan las heridas y se tira para adelante. No pasa nada. La gente que te conoce, y que ve pues que tienes vocación, etc. lo entiende fenomenal. (Norma, 38 años -comenzó con 30-, divorciada, estudios secundarios, directora de entidad privada, en proceso de reproducción asistida; entrevista mayo 2009)

O bien, cuando el embarazo se ha realizado por medios "relativamente" tradicionales sin transgredir la normatividad sexual

Mis padres son muy clásicos, porque son gente clásica, y yo pensé que se iban a escandalizar un poco más. [...] Yo creo que les hubiera extrañado más si lo hubiera hecho de otra manera; si lo hubiera hecho por ahi con un señor que no... raro, una cosa extraña por ahí, un tío que lo ocultas, que se sabe pero que no es... Bueno, esto es una cosa aséptica, esto es la Virgen María. (-Y ya está.) Claro, y entonces... pues esta cultura, en realidad, tiene sus... (risas) (-Su morbo, ¿no?) Claro (...). Sí, una cosa aséptica, es verdad. (-Es cierto.) No hay pecado, no hay sexo. No hay pecado, no hay sexo, entonces esto, mira, hasta la gente más conservadora... Hay aquí, por ejemplo en este Ayuntamiento hay gente muy conservadora, funcionarios, funcionarias, ordenanzas... de esos que no... Me acuerdo de una ordenanza, más clásica que un beso en un portal, ella, la pobre, solterona... que siempre me decía: "Yo, si hubiera existido esto cuando era joven, es que lo hubiera hecho seguro. ¡Es que lo hubiera hecho seguro!". Claro, católica, apostólica, romana... virgen. Claro, ino hay pecado!, jno hay hombre!, ino hay varón!, jlo puedes hacer!, jestá permitido! [...] iLa Virgen María de ahora! (Angelina, 45-50 años -comenzó con 35/40-, soltera, estudios universitarios, empleada en organismo público, 1 hija de 10 años por reproducción asistida; entrevista febrero 2008)

\section{EstRATEGIAS NARRATIVAS DE LEGITIMACIÓN FRENTE A LAS RESISTENCIAS DEL ENTORNO SOCIAL}

Para luchar contra estas resistencias, despliegan "estrategias de camuflaje" encaminadas a que lo nuevo pueda imponerse sin ser cuestionado. Esto explica que, independientemente de la vía de acceso a la maternidad, todas ellas utilicen, de forma recurrente en sus discursos, elementos de la ideología familiar convencional. El primero es la imagen naturalizada y esencialista de la maternidad como algo consustancial a la identidad femenina, representada simbólicamente en la expresión "siempre quise ser madre": 
Es una necesidad de ser madre. ¡A ver! En mi caso, como yo lo he tenido desde siempre... (Kora, 35-40 años, soltera, estudios universitarios, trabajo en consultoría, reproducción asistida en proceso, comienzo en 2006; entrevista mayo 2007)

La verdad es que yo siempre he tenido vocación de ser madre. (Francisca, 40-45 años -comenzó con 35/49-, soltera, estudios universitarios, directora de entidad privada, 1 hija de 0-5 años adoptada en China y de nuevo en proceso de adopción de un segundo hijo; entrevista marzo 2008)

El uso insistente de la locución adverbial "siempre" es un recurso lingüístico con el que estas mujeres buscan normalizar su opción, reclamando una condición común con el resto de mujeres, independientemente de la modalidad elegida para ser madres -en pareja o solas-. En sus relatos se describen como mujeres con vocación de madres, vocación que se han visto obligadas a postergar -en una especie de hibernación- por el cumplimiento de las nuevas expectativas de la sociedad hacia su generación, hecho compartido con otras mujeres que, aún siendo madres en pareja, lo son por primera vez, igual que ellas, a una edad avanzada y por los mismos motivos (estudios, formación, búsqueda de empleo, incorporación al mercado laboral, acceso a una vivienda, etc.). Por lo tanto, no se trata de una renuncia a la pareja ni de un capricho individual, sino que su opción no es más que la consecuencia de un sistema estructural que somete a las mujeres a demandas contradictorias, por un lado, se espera de ellas que asuman con éxito sus nuevos roles en el plano laboral y profesional y, por otro, que sigan ejerciendo los roles tradicionales de madres y esposas en el ámbito doméstico y familiar:

Porque siempre era una opción que yo tenía en la cabeza, de siempre. Yo sé que hay gente que a lo mejor se lo plantea de repente pero, sin embargo, conmigo esa opción siempre convivió. Desde jovencita, jvaya! Lo que pasa que, bueno, pues primero que si la carrera, luego que si encontrar trabajo, luego que si te estabilizas y, en el momento que pasas por la facultad o por la universidad, no es que vayas con retraso, pero hay un tiempo ahi que tienes que dedicarlo a otro tema y, de alguna manera, yo tengo la sensación que retrasas tu vida adulta por terminar tus estudios, luego los cursos de postgrado, y todas estas cosas que hay que hacer después de terminar una carrera para buscarte la vida, que es muy complicado. (Esmeralda, 40 años, soltera, estudios universitarios, técnica en empresa privada, 1 hija de 3 años con "donante conocido"; entrevista abril 2008)

Otro de los esquemas culturales, propio del orden familiar convencional que manejan en sus discursos, es la asociación entre maternidad y emparejamiento como el marco natural para el nacimiento y la crianza de los hijos.

O sea, yo creo que cada vez se lo van a plantear más mujeres sin que sea una cuestión de que no llega el príncipe azul, sino: "Pues yo lo quiero hacer ya, y bueno, como no 
tengo pareja..." ¡Hombre! Para nosotras la... O sea, incluso ella (una participante del foro de MSPE, de 29 años), si ella nos hubiera pedido consejo, nosotras le hubiésemos dicho que esperara, le hubiéramos aconsejado que esperara un poco. ¿Por qué? - iHombre! Porque para nosotras el modelo ideal de crianza es en pareja. (Eulalia, 35-40 años -comienza con 35/40-, soltera, estudios universitarios, free-lance en el mundo del espectáculo, 1 hijo de 0-5 años por reproducción asistida, y ahora continúa para su segundo hijo; entrevista mayo 2007)

Si con la formulación "siempre quise ser madre", buscan integrarse en la condición común de las mujeres como madres, con esta otra, "el modelo ideal de crianza es la pareja", pretenden inscribirse en la corriente principal que opera bajo el patrón cultural imperante que sigue asociando maternidad y emparejamiento. Ambas fórmulas actúan a modo de estrategias discursivas para neutralizar el efecto contra-narrativo y desafiante que la maternidad en solitario puede provocar en su entorno. Son estrategias de encubrimiento con las que pretenden inscribir su relato en la narrativa social dominante sobre la maternidad y la familia contrarrestando el potencial transformador de su opción. Su capacidad de reflexión e identificación de las influencias sociales que necesitan contrarrestar para legitimar su elección es lo que explica estas prácticas discursivas encaminadas a normalizar su decisión de ser madres en solitario. Porque conocen cuáles son las normas culturales, justifican sus intentos de ser madres ajustándose a ellas lo más posible:

Yo esperé hasta los 35 para... bueno, porque es que no considero yo que ésta sea la forma mejor del mundo entero, la de tener un hijo así. Es decir, que si yo hubiera tenido una pareja con la que me hubiera ido bien, aunque solamente hubiera sido una temporada, y con la que hubiera sido posible tener un hijo, y hubiéramos deseado ambos tenerlo y nos hubiéramos decidido a tenerlo... pues probablemente hubiera sido así. Lo hubiera tenido de esa manera. (Angelina, 46 años, -empieza con 34/35 años- soltera, estudios universitarios, empleada en organismo público, 1 hija de 10 años por reproducción asistida; entrevista febrero 2008)

Estas estrategias, en el caso de algunas mujeres, son conscientemente desplegadas para conseguir una contra-argumentación al discurso dominante que deslegitima su opción minoritaria; sin embargo, en otras, se trata de un despliegue de estrategias discursivas interiorizadas como evidentes, "como dadas", desde los espacios colectivos en los que participan, principalmente los foros y la asociación ya citados, con lo cual nos hemos encontrado con algún caso en el que aparece una contradicción entre las prácticas contra-hegemónicas (tanto discursivas como no discursivas) y la negación expresa de cualquier intención reivindicativa o rupturista.

Yo no quiero reivindicar ni la maternidad (para las solteras) ni reivindicar que soy mujer ni modernidades ni nada [...]. Soy una buena madre y no soy luchadora para nada (Lali, 
40-45 años, -comenzó con 35/40-, soltera, estudios secundarios, trabajo en consultoría; 1 hijo y 1 hija mellizos de 0-5 años por reproducción asistida; entrevista abril 2008)

\section{CONCLUSIONES: ASIMILACIÓN DE LA IMAGEN DIFERENCIAL DE LAS MSPE COMO EFECTO BUMERÁN}

La situación ambigua y oscilante que transmiten estas mujeres a través de sus discursos (en los que se entrecruza la percepción que tienen de sí mismas como mujeres empoderadas y autónomas) que les ha permitido explorar una maternidad alternativa (con la percepción que los otros tienen de las MSPE como madres "atípicas", que les obliga a elaborar estrategias de legitimación), acaba desencadenando en ellas un efecto inesperado: la asimilación de la imagen diferencial que los otros proyectan sobre su opción familiar.

No, la gente monoparental, la gente sigue pensando en la señora divorciada, el padre o la madre divorciada. Yo creo que todavía no se ha... la gente no piensa... Porque, claro, madres solteras las hay, pero cuando éstas que se quedaban las pobres... y aquella historia, pero nosotros como tal,... Además el foro ayuda mucho en el sentido de que te ves que no eres un bicho raro. Es que eso es muy importante. (Salomé, 39 años, divorciada, estudios universitarios, profesora instituto, reproducción asistida en proceso; entrevista mayo 2008)

Una diferencia construida socialmente en términos de carencia y privación de una vida familiar "normal" para sus hijos, de ahí la imagen que emerge de sus discursos de una familia "a medias":

A ver, pienso que es una carencia porque va a tener (su futuro hijo/a) una persona menos que la quiera. O en teoría, una persona [...] que le dé apoyo si a mí me pasa algo. Va a tener menos red, o sea, tiene la mitad de personas a su alrededor, la mitad de ayuda. (Norma, 38 años -comenzó con 30-, divorciada, estudios secundarios, directora de entidad privada, embarazada de 4 meses por reproducción asistida; entrevista mayo 2009)

Una familia con la "mitad" de los recursos materiales e inmateriales que tienen, o más bien creen que tienen, aquéllas que se ajustan al patrón biparental; patrón con el que se siguen comparando el resto de opciones familiares en general, y la suya, en particular. El resultado de esta comparación es claramente desfavorable a su proyecto materno-filial. A pesar de haber demostrado su capacidad previsora y su solvencia económica durante y después del proceso (ya sea de adopción, procreación asistida o relaciones sexuales) la concepción dominante sobre la familia convencional acaba marcando la autovalora- 
ción que las MSPE hacen de sus proyectos, no en función de lo que tienen, sino de lo que les falta, representado en esa otra "parte" o "mitad" que supone la presencia, en su caso ausencia, del padre para sus hijos:

Cuando acabó la entrevista le pregunté que cómo veía el tema de la idoneidad, y la trabajadora fue muy clara, todas las familias las deben examinar y analizar a conciencia, pero a los monoparentales el examen es con lupa, y si ya tienen un hijo el examen será mucho mayor, y ahi lo dejó... en agosto cerraban y hasta septiembre no tenía la siguiente entrevista con la pedagoga. Parte de razón no les falta, los monoparentales somos mucho más vulnerables ante cualquier imprevisto, tenemos la mitad de recursos que puede tener una familia biparental, en todos los sentidos, económicos, familiares, tiempo, salud... (Post del Foro adoptarsiendosoltero, febrero 2007)

La carencia no sólo es para sus hijos sino también para ellas, en la medida en que la ausencia del padre es problematizada como la falta de pareja:

En el 90\% de los casos, hay padre y madre; $y$ vas paseando por aquí un sábado, y es hombre y mujer -en el 90\% de los casos-. Y luego, ¿por qué lo veo importante explicarlo? Pues porque va a tener una carencia, y yo he decidido que la tenga [...] una carencia, que es no tener padre. Y eso se lo tengo que explicar. Mi idea ¿vale? Es explicarle que no tiene padre, pero no hacérselo ver como que él tiene un problema por no tener padre. No tiene padre, pues a lo mejor, por el mismo motivo que no tiene hermanos, y que solamente tiene 2 abuelos, y sin embargo, tiene no sé cuántos primos y no sé cuántos tíos. Que es un problema mío porque yo no he conseguido tener pareja. Yo estuve casada pero me separé, y entonces yo ahora mismo no tengo pareja, por eso él no tiene padre. [...] 0 sea, enfocarlo siempre desde que es un problema mío porque yo no he conseguido tener pareja. (Norma, 38 años -comenzó con 30-, divorciada, estudios secundarios, directora de entidad privada, embarazada de 4 meses por reproducción asistida; entrevista mayo 2009)

Debajo de la carencia del padre opera la carencia de la pareja y, con ella, la lógica de la ideología familiar convencional:

Yo quería estar segura de que no iba a perjudicar al niño, eso era lo que más me preocupaba. O que tampoco iba a tomarlo como no tienes pareja, hay una carencia emocional ahí, y de repente lo enfoco, la carencia va a seguir estando alli, ¿sabes?, aunque tengas un niño, no quería que eso pudiese llegar a que luego tuviésemos problemas porque no hubiese pareja, no hubiese un marido en casa... (Rosaura, 45 años, soltera, estudios universitarios, periodista, 1 hija de 5 años por reproducción asistida, comienzo 2002; entrevista mayo 2008) 
Esta imagen deficiente de sus familias, transmitida por los entornos sociales, pero también por los institucionales que regulan el acceso a la maternidad en solitario, contribuye a aumentar la ambivalencia emocional, la disonancia cognitiva y el conflicto personal que se registra en los discursos de las MSPE y que hemos querido analizar en este artículo, como expresión de una paradoja contemporánea y claramente visible en España: la contradicción entre la retórica de la igualdad y la libertad de elección en sociedades democráticas; esto es, entre el discurso de la ciudadanía y las prácticas sociales condicionadas aún por el paradigma de sociedades patriarcales, contradicción que afecta especialmente a las mujeres $y$, en particular, a las que optan por la maternidad en solitario.

\section{RefERENCIAS BibLIOGRÁFICAS}

Alberdi, I. 1999. La nueva familia española. Barcelona: Taurus.

Alberdi. I.; P. Escario y P. Hainovich. 1984. "Actitudes de las mujeres hacia el cambio familiar." Revista Española de Investigaciones Sociológicas 27:41-59.

Beck, U. y E. Beck-Gernsheim. 2003. La individualización. El individualismo institucionalizado y sus consecuencias sociales y politicas. Barcelona: Paidós.

Ben-Ari, A. y G. Weinberg-Kurnik. 2007. "The Dialectics Between the Personal and the Interpersonal in the Experiences of Adoptive Single Mothers by Choice." Sex Roles 56:823-833

Bock, J. S. 2000. "Doing the right thing? Single mother by choice and the struggle for legitimacy." Gender \& Society 14:62-86.

Cea D'Ancona, M. ${ }^{a}$ A. 2007. La deriva del cambio familiar. Hacia formas de convivencia más abiertas y democráticas. Madrid: Centro de Investigaciones Sociológicas.

Flaquer, LI. 1998. El destino de la familia. Barcelona: Ariel.

Flaquer, LI. y J. Soler. 1990. Permanencia y cambio en la familia española. Madrid: Centro de Investigaciones Sociológicas.

González, M.M.; I. Jiménez; B. Morgado y M. Díez. 2008. Madres solas por elección. Análisis de la monoparentalidad emergente. Instituto de la Mujer.

Hertz, R. 2006. Single by chance, mothers by choice: how women are choosing parenthood without marriage and creating the New American Family. Nueva York: Oxford University Press.

Iglesias de Ussel, J. 1998. La familia y el cambio político en España. Madrid: Tecnos.

Inglehart, R. 1990. Culture shift in advanced industrial society. Princeton: Princeton University Press.

Jiménez Godoy, A. B. 2005. Modelos y realidades de la familia actual. Madrid: Fundamentos. 
Jociles, M. ${ }^{a}$ I. y C. Charro. 2008. "Construcción de los roles paternos en los procesos de adopción internacional: el papel de las instituciones intermediarias." Política y Sociedad 45:105-130.

Jones, S. 2008. "Exercising Agency, Becoming a Single Mother." Marriage \& Family Review 42:35-61.

Jordana, O. 2007. "La maternidad voluntariamente sola en Barcelona: una aproximación antropológica". Tesis doctoral, Departamento de Antropología Social, Universidad de Barcelona. Barcelona. (Inédita).

Mannis, V. S. 1999. "Single mothers by choice." Family Relations 48:121-128.

May, V. 2004. "Narrative identity and the re-conceptualization of lone motherhood." Narrative Inquiry 14:169-189.

Meil, G. 1999. La posmodernización de la familia española. Madrid: Acento.

Strauss, A. \& J. Corbin. 1998. Basics of Qualitative Research Techniques and Procedures for Developing Grounded Theory. Londres: Publications.

ANA MARÍA RIVAS es Doctora en Sociología por la Universidad Complutense de Madrid (UCM) y Diplomada en Antropología Social por la Escuela de Altos Estudios en Ciencias Sociales de París. Es Profesora Titular del Departamento de Antropología Social en la UCM. Forma parte de los grupos de investigación Empleo, Género y Cohesión social (EGECO), Work and Family Lives Encounters (WAFLE), es miembro del Instituto Complutense de Sociología para el Estudio de las Transformaciones Sociales Contemporáneas (TRANSOC) y vicepresidenta del Instituto Madrileño de Antropología (IMA). Sus publicaciones e investigaciones se han centrado en las nuevas formas de parentesco y familia (familias reconstituidas, familias transnacionales, monoparentalidad por elección, etc.); mercado laboral, familia y políticas públicas, y antropología del trabajo.

MARÍA ISABEL JOCILES es Doctora en Sociología y profesora titular del Departamento de Antropología Social de la Universidad Complutense de Madrid. Miembro de los grupos de investigación Apsyc -Antropología de las Políticas Públicas y Culturales- y Antropología, salud y educación. Sus principales publicaciones y líneas de investigación han versado sobre metodología/epistemología de la investigación etnográfica, educación -en particular, los modelos formativos en la FP reglada y la escolarización de adolescentes inmigrantes-, procesos de socialización y nuevas formas de familia, e identidades colectivas. Primer Premio Nacional de Investigación Antropológica "Marqués de Lozoya" 1987, del Ministerio de Cultura, dirige actualmente la investigación titulada "Monoparentalidad por elección: estrategias de autodefinición, distinción y legitimación de nuevos modelos familiares" (FEM- 200907717)

BEATRIZ MONCÓ es Doctora en Sociología por la Facultad de Ciencias Políticas y Sociología de la Universidad Complutense. Profesora titular de Universidad en el Departamento de Antropología de la mencionada Facultad. Especialista en antropología del género y antropología de la historia. Miembro del Consejo del Instituto de Investigaciones feministas de la UCM. Miembro del Instituto de Desarrollo y Cooperación de la UCM. Miembro de UNESCO. Miembro de honor de Antropólogos Iberoamericanos en Red. Vicepresidenta del Instituto de Estudios Históricos del sur de Madrid Jiménez de Gregorio.

RECIBIDO: $27 / 06 / 09$

ACEPTADO: $19 / 02 / 10$

Publicado on-line: 27/11/10 